\title{
Revisión de las iniciativas llevadas a cabo en España para implementar la enseñanza de la reanimación cardiopulmonar básica en las escuelas
}

\section{Review of initiatives carried out in Spain to implement teaching of basic cardiopulmonary reanimation in schools}

\author{
Ò. Miró ${ }^{1,2}$, N. Díaz ${ }^{2,3}$, X. Escalada ${ }^{4}$, F.J. Pérez Pueyo ${ }^{5}$, M. Sánchez ${ }^{1,2}$
}

\section{RESUMEN}

La parada cardiorrespiratoria (PCR) es una situación de máxima urgencia médica que potencialmente puede revertirse si se inician maniobras de reanimación cardiopulmonar (RCP) básica de forma inmediata. Sin embargo, esto sucede en menos del $25 \%$ de las PCR presenciadas por los testigos, por lo que es necesario incrementar el conocimiento de estas maniobras en la población general. Una forma de que este conocimiento pueda alcanzar a toda la población es introducir su enseñanza durante la educación obligatoria, como muchas organizaciones especializadas en esta materia recomiendan. Este trabajo analiza las iniciativas llevadas a cabo en este sentido en España, incluyendo la experiencia de los autores en el desarrollo del PROCES, un programa dirigido a los estudiantes de 15 y 16 años que se lleva a cabo desde hace 10 años en la ciudad de Barcelona.

Palabras clave. Parada cardiorrespiratoria. Educación obligatoria.

\begin{abstract}
Cardiorespiratory arrest (CRA) is a situation of maximum medical emergency which can be potentially reversed if basic cardiopulmonary resuscitation manoeuvres (CPR) are provided by the first bystander. Nonetheless, this is done in less than $25 \%$ of the cardiorespiratory arrests (CRA) witnessed by bystanders. Thus, it is urgent to increase the knowledge of such basic CPR manoeuvres among the public in general. One strategy consists in the teaching of basic CPR techniques in schools following the recommendations made by specialized institutions. This study analyzes the initiatives carried out in Spain, including the authors' own experience acquired during the development of PROCES, a program aimed a students from 15 to 16 years of age and carried out during the last 10 years in Barcelona.
\end{abstract}

Key words. Cardiorespiratory arrest. Schools.
1. Área de Urgencias. Hospital Clínic. Barcelona. España

2. Grupo de Investigación "Urgencias: procesos y patologías". IDIBAPS. Barcelona. España

3. Área pedagógica. Escuela de Enseñanza Secundaria Molina. Barcelona. España

4. Sistema de Emergencias Médicas 061. Barcelona. España

5. Departamento Médico. Nestle España. Esplugues de Llobregat. España

Recepción: 26 de septiembre de 2012

Aceptación provisional: 19 de octubre de 2012

Aceptación definitiva: 25 de octubre de 2012

\section{Correspondencia: \\ Dr. Òscar Miró \\ Área de Urgencias \\ Hospital Clínic \\ Villarroel 170 \\ 08036 Barcelona. España \\ E-mail: omiro@clinic.cat}

Ayudas recibidas para este estudio: Los autores han recibido soporte técnico y/o ayudas parciales para llevar a cabo el PROCES durante los 10 últimos años de la Universitat de Barcelona, Ajuntament de Barcelona, Nestle y Laboratorios Menarini, pero dichas ayudas no han tenido ninguna relación con el contenido científico de este trabajo. 


\section{INTRODUCCIÓN}

La muerte súbita como consecuencia de una parada cardiorrespiratoria (PCR) inesperada es la situación de máxima urgencia médica, tanto en el ámbito extrahospitalario $^{1}$ como hospitalario ${ }^{2}$. Así, se calcula que en España, un país con 45 millones de habitantes, sólo por infarto de miocardio se producen más de 25.000 muertes anuales antes que el paciente pueda recibir asistencia médica ${ }^{3}$. Muchas de estas muertes se producen en la vía pública en presencia de otras personas. Se ha comprobado repetidamente que, en esta situación, el porcentaje de fallecimientos supera en $90 \%{ }^{4}$ y que entre los supervivientes más de la mitad presentarán algún tipo de secuela neurológica ${ }^{5}$. Todo ello indica que, teóricamente, se podrían recuperar muchos de estos enfermos si se iniciasen maniobras de RCP básicas que, por otra parte, son relativamente fáciles de proporcionar con un mínimo entrenamiento. A pesar de ello, en menos del $25 \%$ de las PCR presenciadas los testigos inician maniobras de RCP, en parte porque la transmisión de la información no se hace de forma correcta ${ }^{6}$, y en parte porque los testigos no tienen ningún conocimiento en RCP básica que les permita ponerla en marcha hasta la llegada de los sistemas de emergencias médicas SEM). Resulta pues evidente que actualmente la población general está mal preparada para aplicar estas maniobras y que es urgente intensificar los esfuerzos encaminados a incrementar el conocimiento de dichas maniobras de RCP básica y, paralelamente, salvar vidas. Además, es previsible que con la puesta en marcha de nuevas estrategias terapéuticas, tanto durante la RCP (como nuevos fármacos o la desfibrilación in situ por personal no especializado) $)^{7,8}$ como tras la recuperación de una PCR (como la hipotermia precoz) $^{9-11}$, el porcentaje de supervivientes aumente más aún, por lo que esta acción inicial por personal lego resulta básica a todas luces. Además, aún en el caso en el que la recuperación no sea posible, no debe olvidarse que el mantenimiento de una RCP de buena calidad puede contribuir a aumentar el número de donaciones ${ }^{12-15}$. Es por ello por lo que entre los códigos prioritarios desarrollados por diversos sistemas de emergencias médicas (SEM) españoles se encuentra la atención al infarto de miocardio, a la PCR $\mathrm{y}$ al potencial donante en asistolia ${ }^{16-18}$. En este artículo se revisan las iniciativas llevadas a cabo en España para difundir el conocimiento de la RCP entre la población escolar.

\section{LOS ESCOLARES COMO POBLACIÓN DIANA IDEAL PARA LA DIFUSIÓN DE LA RCP A LA POBLACIÓN GENERAL}

Numerosas instituciones y sociedades médicas internacionales, entre ellas la American Heart Association (AHA) o el European Resuscitation Council (ERC), han recomendado que la enseñanza de la RCP básica se introduzca durante la educación obligatoria, ya que la escuela constituye un ámbito ideal para iniciar a la población en el conocimiento y el aprendizaje de las técnicas básicas que forman parte de la RCP. Existen numerosas razones para respaldar esta afirmación. Los jóvenes son una población diana ideal para iniciar programas de difusión amplios, entre otras cosas porque los intentos de adiestrar en RCP básica a la población adulta han sido, en general, descorazonadores. Los jóvenes, a diferencia de los adultos, son más fácilmente asequibles, más capaces de aprender RCP, más interesados en adquirir este tipo de habilidades y, probablemente, más predispuestos a administrarlas en caso necesario ${ }^{19}$. Por otro lado, si programas de este tipo se generalizasen, permitirían preparar a gran parte de la población para ofrecer una respuesta satisfactoria en caso de necesidad, ya que la enseñanza secundaria es obligatoria y todos los ciudadanos pasan por ella.

A todo este teóricamente buen terreno, debe añadirse la buena acogida que este tipo de programas tiene entre la comunidad educativa. Así, siempre que se ha investigado, los docentes, los padres y los alumnos han mostrado un apoyo favo- 
rable a introducir estos conocimientos ${ }^{20}$. Además, la tenencia de estos cursos por parte de la escuela puede suponer, en ciertos entornos, un motivo de discriminación positiva por parte de los padres a la hora de la elección de instituto. No obstante, la enseñanza de las maniobras de RCP básica a adolescentes requiere que se lleve a cabo mediante programas específicamente diseñados para ellos y que se atiendan toda una serie de aspectos pedagógicos que resultan clave para su éxito. Estos programas deben encajarse en las particularidades educativas de cada país e, incluso, de cada ciudad en concreto, ya que lo que puede resultar un buen modelo en un entorno educativo puede no adaptarse a otro. Además de su diseño, el encaje del programa dentro de la actividad educativa ordinaria también es vital para que pueda llevarse a cabo, y contar de forma irrenunciable con la participación de los profesores del centro ${ }^{20}$. Finalmente, la edad de los participantes es también un aspecto determinante del éxito, ya que debe ser la suficiente para asegurar madurez para poder incorporar los conceptos, habilidades y actitudes necesarias para realizar la RCP básica con suficiencia.

En este sentido, durante los años 60, Noruega fue uno de los primeros países en promover la enseñanza de la RCP básica a los escolares ${ }^{21}$. Estas estrategias posteriormente se han diseminado, en algunos casos con proyectos ambiciosos por su extensión como el llevado a cabo por Isbye y col en Dinamarca ${ }^{22}$, con resultados cada vez mejores y, en ocasiones, con vidas salvadas derivadas directamente de estos programas ${ }^{23}$. Tal vez uno de los países en los que se ha conseguido un programa más estable de RCP básica en las escuelas sea Canadá. Allí se puso en marcha hace ya una década un programa obligatorio de RCP básica en sus institutos (high schools), que en la actualidad ya engloba en muchos de sus estados la totalidad de centros, con más de 25.000 alumnos participantes cada año. El programa cuenta con el apoyo altruista de empresas privadas, las cuales permiten el acceso de los centros y los alumnos al material nece- sario. Además, el programa incluye otros aspectos colaterales beneficiosos importantes para la población juvenil, como el mantenimiento de estilos de vida saludables $^{24,25}$.

\section{LA EXPERIENCIA EN ESPAÑA}

En España han existido múltiples iniciativas para trasladar los conocimientos de la RCP básica a la escuela. Son múltiples los colectivos que de una forma local han puesto en marcha cursos o actividades en torno a la RCP. En este sentido, los SEM han jugado un papel importante en muchos de estos casos, pues no en balde uno de sus objetivos es la prevención de las situaciones de riesgo entre la ciudadanía ${ }^{26-28}$. En ocasiones, se trata de actividades puntuales y limitadas en el tiempo que no han tenido continuidad, pero en otras cuentan con una larga tradición. Tal es, por ejemplo, el caso del "Programa Alertante" del SAMUR en la ciudad de Madrid, el cual se lleva a cabo desde hace más de 10 años. En él se ofrece formación a escolares de 10 a 18 años de forma gratuita para todos aquellos centros educativos que la solici$\tan ^{29}$. En esta misma línea, es de destacar la actividad de enseñanza de la RCP para estudiantes de educación secundaria que incluyen los congresos nacionales de la Sociedad Española de Medicina de Urgencias y Emergencias (SEMES) y por la que ya han pasado más de 2.000 alumnos ${ }^{30}$. En este sentido, resulta también interesante conocer el programa puesto en marcha por la asociación "El ABC que salva vidas" ${ }^{31}$, en la cual el Gobierno de Navarra y en concreto los médicos del Sistema de Emergencias de Navarra juegan un papel destacado. La participación en el proyecto de la Universidad Pública de Navarra y de la Irish Heart Foundation sin duda conceden empaque al proyecto. Como la asociación expresa, es deseable en toda la población el conocimiento sobre cómo actuar ante una persona inconsciente, sobre las técnicas de reanimación cardiopulmonar y sobre la cadena de supervivencia y, en este sentido, el programa se compromete a difundir este conocimiento. Entre 
las poblaciones diana a las que se dirige el programa, la comunidad escolar ocupa un lugar destacado. Así, dos escuelas (el colegio Santa María la Real de Sarriguren y el colegio público San Miguel de Aoiz) ya han iniciado esta formación, y aunque no se dispone de datos, será muy interesante conocer en un futuro los resultados de esta experiencia, así como la expansión que alcanza el programa. El sentido de responsabilidad hacia la comunidad une a los miembros y colaboradores de la asociación a ofrecer de forma altruista su tiempo y esfuerzo para difundir una habilidad básica en la población y de esa forma contribuir a salvar vidas de personas que de modo repentino pueden sufrir una parada cardiorrespiratoria.

Por otro lado, en España también existen programas que intentan profundizar de una manera científica en los resultados obtenidos con la finalidad de definir el mejor escenario y las mejores herramientas para alcanzar los resultados más óptimos. En este sentido, se ha realizado una búsqueda a través de MedLine y Web of Knowledge, dos de los buscadores más importantes de trabajos científicos en biomedicina, cruzando los descriptores Cardiopulmonary resuscitation o Resuscitation manoeuvres con High school o Teaching $C P R$ y con Spain en el campo identificativo de la nacionalidad de los autores. Además, se consultaron las referencias cruzadas de los artículos encontrados y aquellos de los cuales los autores conocían de su existencia de primera mano. Ello ha permitido encontrar experiencias publicadas desarrolladas en Galicia, Aragón y Cataluña. Tal es el caso del programa "RCP na aula", que se está llevando a cabo en Lugo ${ }^{32}$ con gran aceptación, y que está pendiente de analizar los resultados de una apuesta de formación basada en los propios profesores de secundaria. Ésta incluye el reciclaje formativo del estudiante desde el primer curso de la enseñanza secundaria obligatoria (ESO) hasta el primer curso de bachillerato. De una forma similar, en las comarcas del sur de Tarragona se está llevando a cabo un interesante programa en el que se pretende instaurar de una forma pro- gresiva, en lo que los autores denominan "Formación en espiral", conceptos de RCP básica en todos los niveles de la enseñanza obligatoria, desde educación infantil (P 3 años) hasta segundo de bachillerato (18 años) $)^{33,34}$. Será muy importante conocer los resultados en términos de aceptación, rendimiento y costes que se obtiene con este programa para valorar su posible desarrollo en un marco más general. Recientemente, un grupo de investigación aragonés ha desarrollado un videojuego que simula una RCP básica, el cual se complementa con vídeos, hecho que lo convierte en una iniciativa pionera en España ${ }^{35}$. El videojuego tiene además la virtud que se ofrece como software libre gratuito ${ }^{36}$. La instrucción con dicha herramienta formativa obtiene unos resultados razonablemente buenos, si bien no alcanza los niveles de rendimiento que se consiguen con una formación más reglada, basada en un instructor acreditado en RCP. En cualquier caso, es una nueva iniciativa que además puede incorporarse en otros programas que se desarrollen actualmente o en el futuro, y que puede permitir reforzar su poder didáctico en una población en edad escolar, en la que el diseño pedagógico de los programas que se implementen en ella es vital para su éxito ${ }^{37}$.

En este sentido, el Programa de Reanimación cardiopulmonar Orientado a Centros de Educación Secundaria (PROCES) es posiblemente el programa con mayor duración experimentado hasta ahora, el cual ha aportado interesantes resultados y ha conferido a los autores del presente artículo cierta experiencia con los aspectos particulares de este tipo de programas y que se discuten a continuación ${ }^{38,39}$.

\section{EXPERIENCIA EN BARCELONA: EL PLANTEAMIENTO DEL PROCES}

El actual marco educativo catalán, con la posibilidad que éste ofrece de incorporar programas adaptados a las necesidades e inquietudes de los alumnos de Enseñanza Secundaria Obligatoria (ESO), brinda una oportunidad única para poner 
en marcha las recomendaciones anteriormente mencionadas. En este contexto, en el año 2002 se puso en marcha el PROCES cuya finalidad última era difundir el conocimiento de la RCP básica a la población general mediante su enseñanza en la escuela. Se trataba de demostrar su factibilidad y de sensibilizar a las administraciones de la necesidad de generalizar dicho programa.

El PROCES fue especialmente diseñado para poder ser incorporado al material curricular de los chicos de entre 14 y 16 años en sus centros educativos, por lo que los aspectos pedagógicos se identificaron como un factor clave para el éxito del programa. La estructura formal del PROCES se basa en los criterios universalmente aceptados en RCP básica siguiendo las directrices de la $\mathrm{AMA}^{40}$, y está adaptado desde el punto de vista pedagógico a la población diana a la cual va dirigido el programa (alumnos de 15 y 16 años). Inicialmente se elaboró y/o adquirió el material necesario para el profesor (manual), para los alumnos (manual del alumno, tríptico) y para el aula (transparencias, CD-ROM de soporte para las explicaciones teóricas y maniquís de RCP básica para las clases prácticas). Fue posible disponer de todo este material, de los docentes médicos y de las instalaciones necesarias gracias a la colaboración desinteresada de entes públicos (Hospital Clínic de Barcelona, Facultad de Medicina de la Universidad de Barcelona, Sistema de Emergencias Médicas de Catalunya, Área de Educación del Ayuntamiento de Barcelona) y privados (Departamento Médico de Nestle España, Escuela de Educación Secundaria Molina). Todo este material (editado en catalán) está disponible libremente para aquellos centros y autores interesados que así lo soliciten directamente a los autores.

La operativa del programa se diseñó siguiendo el plan educativo actual en Barcelona y se ofreció su incorporación a los créditos variables, y siempre que fuese posible, a créditos variables relacionados con la salud. En otras ocasiones, se impartió en la asignatura de ciencias naturales, donde algunos de los contenidos curricu- lares se corresponden con los del programa. El PROCES se estructuró en 7 sesiones independientes, para cada una de las cuales se consignaron los objetivos (detallándose individualmente los conceptos, procedimientos y actitudes específicos), las actividades y los recursos materiales y humanos, puesto que ésta es la forma habitual en la que se organizan los programas educativos por parte de los docentes en la enseñanza secundaria. Con la finalidad de crear interés entre los estudiantes, se dieron títulos llamativos a las 7 sesiones, y se encargaron ilustraciones para los manuales y el material de soporte de dichas sesiones de acuerdo con la estética juvenil actual. En la primera sesión (“¿Estamos preparados?"), se reflexiona sobre la magnitud del problema que supone la muerte súbita en el mundo occidental y se presentan las pautas generales del PROCES. En la segunda sesión ("Informándonos"), se realiza un repaso a los conceptos mínimos de anatomía y fisiología que el estudiante debe poseer para entender en qué consiste una PCR y en qué se basa la RCP, conceptos muchos de ellos incluidos (y ya explicados) en el contenido curricular de ciencias naturales. En la tercera sesión (“¿Cómo morimos?”), se explican los diferentes mecanismos por los que puede acontecer una PCR. En la cuarta sesión ("Cadena de supervivencia"), se explica la forma de reconocer una PCR y los eslabones básicos que deben activarse en caso de que se produzca una PCR. En la quinta sesión ("Volviendo a la vida"), se explican y practican las técnicas de RCP básicas propiamente dichas. En la sexta sesión ("Escenificando"), se realiza una puesta a punto de todos los conocimientos previos en una simulación de PCR. En la séptima y última (“¡Ahora sí!”), se lleva a cabo una recapitulación de todo el programa y se propicia un foro de debate abierto en el aula. Se acordó que para una mayor implicación con el PROCES por parte del centro educativo era necesario que una parte del temario fuese desarrollada por los profesores del centro (las 4 primeras sesiones teóricas, 4 horas) y otra por profesionales sanitarios (las 2 sesiones prácticas "Vol- 
viendo a la vida" y "Escenificando", 4 horas), y que la última sesión de síntesis (1 hora) fuese impartida en forma de tutoría por el profesor contando con soporte audiovisual obtenido in situ durante la realización de las clases prácticas.

La parte teórica del PROCES que debían impartir los profesores del centro contiene conceptos que ya se incluyen en el currículo de secundaria y que se encuentran detallados en el manual del profesor. Además, los profesores asistieron a una sesión previa en la que se hizo hincapié en los aspectos más importantes que debían subrayar durante su explicación. De forma adicional a los conocimientos propios en RCP básica adquiridos a lo largo del programa, el PROCES incorpora en esta última sesión una serie de recortes de prensa respecto a temas directa o indirectamente relacionados con la RCP básica que permiten generar el debate en el aula y que se consideró que podían contribuir a enriquecer el proceso madurativo del adolescente. Las clases prácticas llevadas a cabo por el personal sanitario (sesiones 5 y 6) se realizaron inicialmente en el propio centro educativo, con una relación de instructor-alumno de 1:12 y maniquí-alumno de 1:6. El tiempo mínimo de RCP por alumno fue de 15 minutos y se consideró la sesión finalizada cuando más del $90 \%$ de los alumnos conseguía una secuencia adecuada de RCP y sus maniobras eran correctas, a juzgar por el sistema de detección automática del maniquí y por la observación de los profesionales sanitarios.

\section{RESULTADOS ALCANZADOS POR EL PROCES}

El PROCES se realizó inicialmente de forma piloto sin coste alguno en 12 aulas de segundo ciclo de secundaria de 4 centros públicos (8 aulas) y 4 centros privados concertados (4 aulas) durante el curso académico 2002-2003 ${ }^{38}$. Se realizó a todos los participantes una prueba de 20 preguntas (10 acerca de nociones de fisiopatología, que se exponen en las sesiones teóricas, y 10 referentes a la práctica de la
RCP-básica, que se exponen en las sesiones teórico-prácticas) de elección múltiple antes y después de realizar el PROCES, para valorar la progresión en conocimientos teóricos y prácticos. Se consideró que el aprendizaje había sido satisfactorio si tras la realización del PROCES se contestaban bien al menos 8 de las 10 preguntas referentes a la práctica de la RCP. Al final del PROCES también se realizaron encuestas de opinión tanto a los profesores como a los estudiantes, con la finalidad de identificar áreas de mejora en el proyecto.

Los resultados de este programa piloto fueron muy satisfactorios ${ }^{38}$. La acogida del PROCES en los centros en que se llevó a cabo fue excelente, tanto por parte de los estudiantes como de los profesores. La valoración (sobre 10 puntos) que los participantes en el PROCES hicieron del desarrollo de los conceptos teóricos fue de 7,9; de los de RCP básica, 8,2, y de las prácticas, 8,4. Los resultados obtenidos constataron un incremento significativo en los conocimientos teóricos y prácticos respecto a la RCP básica por parte de los alumnos tras la realización del PROCES, aunque con un mayor margen de mejora en los primeros, que es en los que se registra un menor progreso. Globalmente, la puntuación de los alumnos obtenida en el test de conocimientos, sobre un máximo de 20 puntos, pasó de una media de 8,5 antes del PROCES a 13,5 tras su realización Esta experiencia inicial permitió concluir que el PROCES era un instrumento válido para incrementar los conocimientos en RCP-básica en la población general, sin grandes limitaciones asociadas en función de las características del alumno o el centro, aunque había ciertas tendencias que era necesario explorar. Entre ellas, el rendimiento de las chicas y de los alumnos sin intención de cursar estudios en áreas de ciencias de la salud fue sensiblemente superior al resto. Además, tanto alumnos como profesores de secundaria que participaron identificaron áreas de mejora en algunos capítulos específicos del PROCES.

Con posterioridad, se han introducido algunas modificaciones, esencialmente organizativas, con la finalidad de llegar mejor 
y a más alumnos mediante la simplificación de la propuesta del curso. Entre ellas, el que los profesores de secundaria se hiciesen cargo de la ejecución completa del programa, tanto de la parte teórica como de la parte práctica. Para poder llevar a cabo esta última, se capacitó específicamente a los profesores del centro mediante un curso de 6 horas como formadores en RCP básica. Este curso es de repetición obligatoria anual para poder tener acceso al programa. Con posterioridad, comparamos los rendimientos de los alumnos que habían realizado el PROCES a través de esta nueva dinámica y pudimos comprobar que los alumnos formados exclusivamente por el profesorado del centro educativo alcanzaron, al menos, igual rendimiento que los que desarrollaron el programa con una estructura docente mixta (profesores del centro y profesionales sanitarios) y que, incluso, la persistencia de conocimientos prácticos al cabo de un año era superior con la nueva metodología ${ }^{41}$.

Respecto a la persistencia de conocimientos, éste es un hecho bien conocido que tanto conocimientos como habilidades en RCP decrecen con el tiempo. Esto hemos podido constatarlo también con el PROCES: mientras que justo tras finalizar el programa el $57 \%$ de los participantes podía considerarse, que presentaban un aprendizaje satisfactorio, este porcentaje descendía al $37 \%$ cuando se repetía el mismo test al cabo de un año de realizado el curso ${ }^{36}$. Cuando se comparan estos rendimientos con otros colectivos que son instruidos en RCP básica a través de cursos reglados con una mayor trayectoria, y en el caso del PROCES lo comparamos con cadetes de policía que siguieron un curso de RCP de la AHA, hemos constatado que el aprendizaje satisfactorio inicial conseguido con el PROCES fue claramente inferior (57\% frente a $79 \%$ los cadetes), pero en cambio la persistencia fue superior en los estudiantes de secundaria (37\% frente a $23 \%)^{42}$.

Globalmente, y tras 10 años de puesta en marcha del programa, los resultados del PROCES han permitido perfilar algunos aspectos importantes. Los más de
3.000 alumnos formados gracias al programa han puntuado muy bien de forma mantenida el programa, al igual que lo han hecho sus profesores. Los porcentajes de aprendizaje satisfactorio rozan el $60 \%$, con un mejor rendimiento en los conceptos prácticos que en los teóricos y con una buena persistencia de los mismos al cabo de un año, cuando alrededor del $40 \%$ de los alumnos aún mantienen unos conocimientos globales satisfactorios. Hemos objetivado que los centros privados, los centros situados en distritos de baja renta per cápita, el desarrollo del PROCES íntegramente por profesores del centro y la ausencia de asignaturas pendientes de cursos previos por parte del alumno se relacionan de forma independiente con un mejor rendimiento inmediato, en tanto que sólo los dos últimos son los que guardan una relación significativa con la persistencia del aprendizaje ${ }^{39}$.

\section{OPORTUNIDADES Y DIFICULTADES EN LA DIFUSIÓN DE LA RCP EN ESCUELAS EN ESPAÑA}

El PROCES, en manos de médicos especialistas en urgencias y emergencias, es una herramienta excelente para difundir los conocimientos en RCP entre los alumnos de ESO. Su afianzamiento durante los próximos años, así como su incorporación al currículo, pasan necesariamente por una apuesta clara y decidida de las administraciones públicas implicadas ${ }^{42,43}$. Con todo, hemos podido descubrir una serie de condicionantes, en positivo y en negativo, que pueden ser extrapolados a otros entornos semejantes, y que deben ser tenidos en cuenta en todo intento similar de introducir un programa de RCP para escolares. La tabla 1 recoge los puntos más importantes. Los autores somos defensores convencidos de la factibilidad de este tipo de programas, aunque las dificultades de implantación y, sobre todo, de perpetuación son grandes. No obstante, ello no debe oscurecer las enormes ventajas que supone para la comunidad en la que se aplica su implantación. 
Tabla 1. Principales aspectos a tener en cuenta para la puesta en marcha y mantenimiento de un programa de reanimación cardiopulmonar básica en escuelas

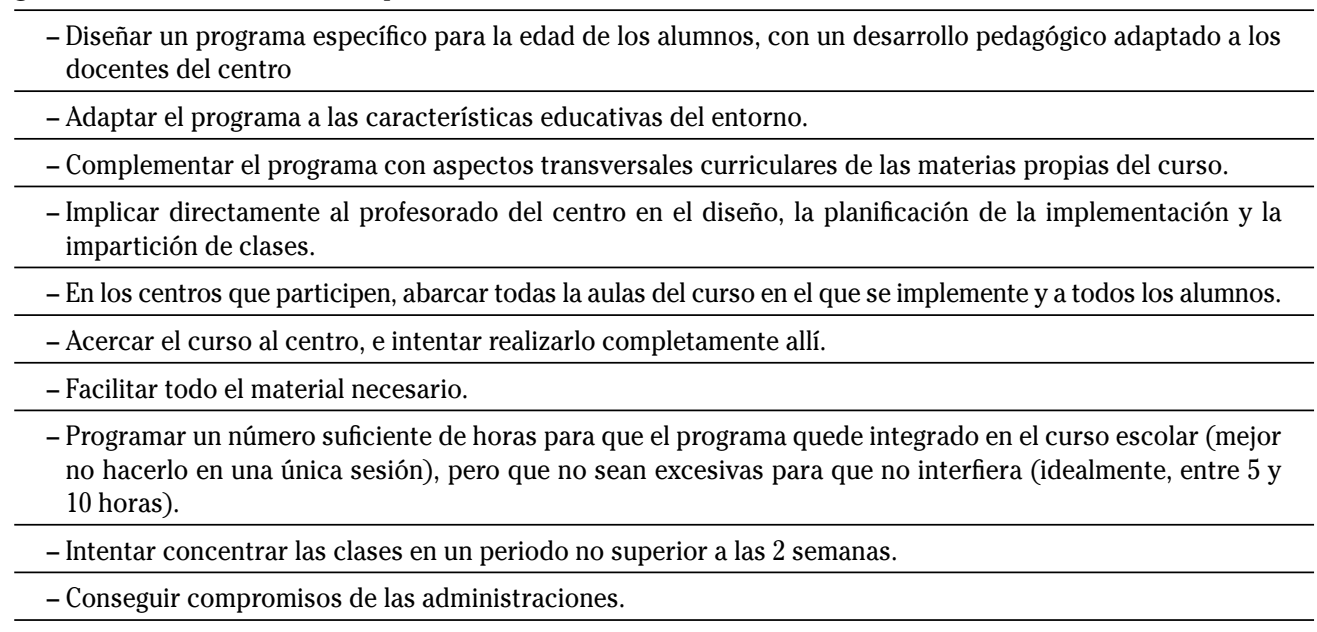

Probablemente merece una mención especial, en los momentos de crisis económica que atraviesa Europa en general y España en particular, los costes que puede suponer la implantación de un programa de este tipo de forma generalizada en España. No conocemos estudios que permitan afirmar rotundamente que esta política de formación resulta coste-beneficiosa. Sin embargo, debemos pensar que son posibles modelos que abaraten al máximo la implantación de estos cursos, huyendo del ánimo de lucro, y además debemos buscar la complicidad de iniciativas privadas en cuyos principios fundacionales se encuentre la mejora de la calidad de vida en la población, de manera que se abaraten los costes. Por otro lado, resulta más difícil cuantificar económicamente las muertes y lesiones graves secundarias evitadas al atender precoz y correctamente una parada cardiorrespiratoria. Deberemos, pues, esgrimir con inteligencia estos argumentos frente a las administraciones correspondientes para implantar un programa de este tipo a nivel nacional. Quizás así en el horizonte de las próximas décadas podamos incluir una población más preparada para hacer frente a una PCR en la vía pública y unas probabilidades de supervivencia para los pacientes que la padezcan mayores a las actuales ${ }^{44-46}$.

\section{BIBLIOGRAFÍA}

1. López-Messa JB, Alonso-Fernández JI, Andrés-De Llano JM, Garmendia-Leiza JR, ARdura-FernándeZ J, De CAstro-Rodríguez $\mathrm{F}$ et al. Características generales de la parada cardiaca extrahospitalaria registrada por un servicio de emergencias médicas. Emergencias 2012; 24: 28-34.

2. Fontanals J, Miró O, Pastor X, Grau JM, Torres A, ZaVAla E. Reanimación cardiopulmonar en enfermos hospitalizados en unidades convencionales. Estudio prospectivo de 356 casos consecutivos. Med Clin (Barc) 1997; 108: 441-445.

3. Marrugat J, Elosua R, Marti H. Epidemiology of ischaemic heart disease in Spain: estimation of the number of cases and trends from 1997 to 2005. Rev Esp Cardiol 2002; 55: 337-346.

4. Callans DJ. Out-of-hospital cardiac arrest, the solution is shocking. N Engl J Med 2004; 351: 632-634.

5. Herlitz J, Andersson E, Bang A, Engdahl J, HolMBERG M, LindQVist $J$ et al. Experiences from treatment of out-of-hospital cardiac arrest during 17 years in Göteborg. Eur Heart J 2000; 21: 1251-1258.

6. Mateos Rodríguez A, Vegas Gómez E, Rodríguez Rodil N. Motivo de consulta telefónica en las paradas cardiorrespiratorias. Emergencias 2009; 21: 235-236.

7. Fernández Gallego V, Sorribes Del Castillo J, MANRIQUe MaRTínez I. Actualización de la normativa sobre formación y utilización de desfibriladores semiautomáticos en España. Emergencias 2010; 22: 316-318. 
8. Nolan JP, Soar J, Zideman DA, Biarent D, BosSAERT LL, DEAKIN C et al. European Resuscitation Council Guidelines for Resuscitation 2010 Section 1. Executive summary. Resuscitation 2010; 81: 1219-1276.

9. Boix Alonso H, Castilla Fernández Y. Hipotermia durante el transporte neonatal en la encefalopatía hipóxico-isquémica. Emergencias 2011; 23: 336-337.

10. Corral Torres E, Fernández Avilés F, López De Sa E, Martín Benítez JC, Montejo JC, Martín Reyes $\mathrm{R}$ et al. La aplicación de hipotermia moderada tras la reanimación cardiaca iniciada en el medio extrahospitalario puede incrementar la supervivencia sin deterioro neurológico. Estudio de casos y controles. Emergencias 2012; 24: 7-12.

11. Barreña Oceja I, Gil Martín FJ, García De Vicuña Meléndez A, Rodríguez Delgadillo MA, Gutiérrez Herrador G, Vázquez Naveira MP. Resultados de la puesta en marcha de un protocolo de hipotermia terapéutica en la parada cardiaca consensuado entre un sistema de emergencias médicas y un servicio de urgencias hospitalario. Emergencias 2012; 24: 39-43.

12. Mateos Rodríguez AA, Navalpotro Pascual JM, Martín Maldonado ME, Barba Alonso C, Pardillos Ferrer L, Andrés Belmonte A. Aplicación de cardiocompresores mecánicos en el donante tras una muerte cardiaca extrahospitalaria. Emergencias 2010; 22: 264-268.

13. Mateos Rodríguez AA, Cepas Vázquez J, Navalpotro Pascual JM, Martín Maldonado ME, Barba Alonso C, Pardillos Ferrer L et al. Análisis de cuatro años de funcionamiento de un programa de donante a corazón parado extrahospitalario. Emergencias 2010; 22: 96-100.

14. Rodríguez Serrano D, Del Río Gallegos F, Gordo VidAl F, SÁnchez M. Donantes tras la muerte cardiaca. Emergencias 2011; 23: 496.

15. Mateos Rodríguez A, Sánchez Brunete Ingelmo V, Navalpotro Pascual JM, Barba Alonso C, Martín MaLdonado ME. Actitud de los profesionales de emergencia ante la donación de órganos tras una muerte cardiaca. Emergencias 2011; 23: 204-207.

16. Jiménez FÀbrega X, Espilla JL. Códigos de activación en urgencias y emergencias. La importancia de priorizar. An Sist Sanit Navar 2010; 33 (Supl. 1): 77-88.

17. Jiménez Fàbrega X, Espila Etxeberria JL, Gallardo Mena J. Códigos de activación: pasado, presente y futuro en España. Emergencias 2011; 23: 311-318.

18. Pacheco A, Burusco S, Senosiain MV. Prevalencia de procesos y patologías atendidos por los servicios de emergencia médica extrahospitalaria en España. An Sist Sanit Navar 2010; 33 (Supl. 1): 37-46.

19. Jelinek G, Gennat H, Celenza T, O'Brien D, JaCoBs I, LYNCH D. Community attitudes towards performing cardiopulmonary resuscitation in Western Australia. Resuscitation 2001; 51: 239-246.

20. Miró O, Jiménez-Fábrega X, Espígol G, Cullá A, Escalada Roig X, Díaz N et al. Teaching basic life support to 12-16 year olds in Barcelona schools: Views of head teachers. Resuscitation 2006; 70: 107-116.

21. LiND B. Teaching mouth-to-mouth resuscitation in primary schools. Acta Anaesth Scand 1961; 9: 63-69.

22. Isbye DL, Rasmussen LS, Ringsted C, Lippert FK. Disseminating cardiopulmonary resuscitation training by distributing 35,000 personal manikins among school children. Circulation 2007; 116: 1380-1385.

23. Drezner JA, Rao Al, Heistand J, Bloomingdale MK, HARMON KG. Effectiveness of emergency response planning for sudden cardiac arrest in United States high schools with automated external defibrillators. Circulation 2009; 120: 518-525.

24. Advanced Coronary treatment (ACT) Foundation. High School CPR [Consultado 10/2003]. Disponible en: http://www.actfoundation.ca

25. Liberman M, Golberg N, Mulder D, Sampalis J. Teaching cardiopulmonary resuscitation to CEGEP students in Quebec. A pilot project. Resuscitation 2000; 47: 249-257.

26. Sesma J, MiRó O. Urgencias y emergencias: al servicio del ciudadano. An Sist Sanit Navar 2010; 33 (Supl. 1): 5-6.

27. Jiménez Murillo L, Montero Pérez FJ. Complejidad de la asistencia médica urgente en la España del siglo XXI. An Sist Sanit Navar 2010; 33 (Supl. 1): 7-12.

28. The Core Curriculum and Education Committee for the International Federation for Emergency Medicine. Modelo de Plan de Estudios de la Federación Internacional de Medicina de Emergencias para los Especialistas de Medicina de Urgencias y Emergencias. Emergencias 2011; 23: 394-409.

29. SAMUR-Protección civil. Programa alertante. Consultado el 08/08/2012. Disponible en: https://www.munimadrid.es/portal/site/munimadrid/menuitem.f4bb5b953cd0b0aa7d24 5 f019fc08a0c/?vgnextoid $=\mathrm{c} 88$ fcdb1bfffa010V gnVCM100000d90ca8c0RCRD\&vgnextchann el=84516c77e7d2f010VgnVCM1000000b205a 0aRCRD\&idCapitulo $=4328860$ 
30. Menarini. Area de prensa. 300 alumnos de secundaria de Tarragona inauguran el Congreso Nacional de Urgencias. Consultado el 09/08/2012. Disponible en: http://www.menarini.es/sala-de-prensa/notas-de-prensa/2479. html

31. El ABC que salva vidas. Consultado el 23-102012. Disponible en: http://www.elabcquesalvavidas.org

32. López Unanua MC, Freire Tellado M, Rasines Sisniega R, Iglesias GonzÁlez A. RCP na aula: programa de enseñanza de la reanimación cardiopulmonar básica para estudiantes de secundaria Emergencias 2012; 24: 76.

33. Cerdà Vila M, Chanovas Borras M, Espuny Vidal C, Escalada Roig X, Grupo de trabajo de SVB a Educació de Terres del Ebre. Plan piloto de formación en soporte vital básico en las escuelas. Formación en espiral. Emergencias 2009; 21: 76.

34. Cerdà M, Chanovas Borras M, Escalada Roig X, Espuny Vidal C, Grupo de trabajo de SVB a Educació de Terres del Ebre. Pilot plan for training in life support and CPR in schools. Med Intensiva 2012; 36: 158-159.

35. Marchiori EJ, Ferrer G, Fernández-Manjón B, Povar-Marco J, Suberviola JF, Gimenez-Valverde A. Instrucción en maniobras de soporte vital básico mediante videojuegos: comparación de resultados frente a un grupo control. Emergencias 2012; 24: 433-437.

36. Adventure e-learning games. Primeros auxilios. Consultado el: 03/08/2012. Disponible en: http://e-adventure.e-ucm.es/course/ view.php?id=25

37. Miró O, Díaz N, SÁnchez M. Aprender reanimación cardiopulmonar desde la escuela. Emergencias 2012, 24; 423-425.

38. Miró O, Jiménez-Fábrega X, Díaz N, Coll-Vinent B, Bragulat E, Jiménez $\mathrm{S}$ et al. Programa de
Reanimación cardiopulmonar Orientado a Centros de Enseñanza Secundaria (PROCES): análisis de los resultados del estudio piloto. Med Clin (Barc) 2005; 124: 4-9.

39. Miró O, Escalada X, Jiménez-Fábrega X, Díaz N, Sanclemente G, Gómez X et al. Programa de Reanimación Cardiopulmonar Orientado a Centros de Enseñanza Secundaria (PROCES): Conclusiones tras 5 años de experiencia. Emergencias 2008; 20: 229-236.

40. American Heart Association. Heartsaver CPR in the schools: Student manual. Dallas: American Heart Association National Center; 2001. p. $1-28$

41. Jiménez-Fábrega X, Escalada-Roig X, Miró O, SANClemente G, Díaz N, Gómez X et al. Comparison between exclusively school teacher-based and mixed school teacher and healthcare provider-based programme on basic cardiopulmonary resuscitation for secondary schools. Emerg Med J 2009; 26: 648-652.

42. JimÉnez-Fábrega X, Escalada-Roig X, SÁnchez M, Culla A, Díaz N, Gómez X et al. Results achieved by emergency physicians in teaching basic cardiopulmonary resuscitation to secondary school students. Eur J Emerg Med 2009; 16: 139-144.

43. Miró O, SÁnchez M, Jiménez-FÁbrega X, EscALADA-RoIG $X$. Teaching basic life support in schools: still waiting for public funding. Resuscitation 2008; 77: 420-421.

44. MiRó O. ¿Hacia donde caminamos? Urgencias 2030. An Sist Sanit Navar 2010; 33 (Supl. 1): 229-235.

45. Miro O. Especialidad de Medicina de Urgencias y Emergencias: necesaria y querida. Emergencias 2010; 22: 321-322.

46. Flores CR. La saturación de los servicios de urgencias: una llamada a la unidad. Emergencias 2011; 23: 59-64. 